\title{
Regional gap in human capital: determinants of education and urbanization
}

\author{
Aida Guliyeva ${ }^{1 *}$, Liliya Averina ${ }^{2}$, Oleg Grebennikov ${ }^{2}$, and Alexander Shpakov ${ }^{2}$ \\ ${ }^{1}$ Azerbaijan State University of Economics, "SABAH" center, UNEC, Istiqlaliyyat str. 6, Baku, \\ Azerbaijan \\ ${ }^{2}$ Kuban State University, 149 Stavropolskaya str., Krasnodar, 350040, Russian Federation
}

\begin{abstract}
This paper studies the regional gap in human capital. Specifically, it focuses on the important determinants of this capital represented by such key factors as education and urbanization. We stress the importance of human capital for the economic growth and show how it can be important for the effective development of both urban and rural areas. This study examines the regional distribution and dynamics of human capital. Human capital is credited with a crucial role in the creation of economic growth. Additionally, we investigate how the exposure to the urban or rural environment affects the educational success of people worldwide. In addition, our paper studies the effects of migration on urbanization and education. Our results show that institutional factors can be a good proxy for explaining the relationship between human capital development and urbanization. Furthermore, it can be concluded that return to education is higher in urban areas compared to rural areas, and higher in highly educated cities compared to smaller towns. All of these creates some important implications for urbanization and education that can be used by the policymakers and urban and rural planners for narrowing the regional gap in human capital and increasing the overall well-being and economic growth.
\end{abstract}

Keywords: urbanization, human capital, regional divide, urban and rural areas.

\section{Introduction}

Education and urbanization currently represent two important patterns for the development of human capital. Particularly education is strongly linked to migration in the areas with educational effects, with clear patterns [1,2]. Estimates based on the data from some countries suggest that a 10-percentage point increase in the proportion of urban population is associated with an average increase in education of more than 1 month [3]. However, this also indicates a regional gap in human capital formation with urban population having a comparative advantage over the rural one [4].

For instance, in a given typical EU or OECD country where $20 \%$ of the population live in agglomerations, an average length of education is around 12 years [5]. Education is a key indicator of human capital and is considered one of the main determinants of internal and

\footnotetext{
*Corresponding author: guliyevaaida@ymail.com
} 
external migration $[6,7]$. Previous studies suggest that human capital is at the expense of rural areas in urban areas $[8,9]$. Based on the theory of migration selection, the study of the relationship between characteristics of human capital and internal migration starts from the assumption that education acts as a fundamental motor for the movement and mobility of skills from rural to developed areas and from urban to developed areas [10]. The mobility of qualifications in relation to other types of internal migration such as urban versus rural is not taken into account in relation to this mobility. Utilizing administrative data, it has been found that children growing up in urban areas achieve a higher level of human capital than children in rural areas due to observed cognitive abilities and various family traits [11]. Additionally, immigrants with higher levels of human capital tend to come from metropolitan regions. It is well known that there is fewer human capital in rural areas. Differences between urban and rural areas are an important study area for the economic and social development of developing countries. Recent data show how the population is growing impacting on the unprecedently high level of urbanization in the largest cities around the globe (see Figure 1 that is presented below).

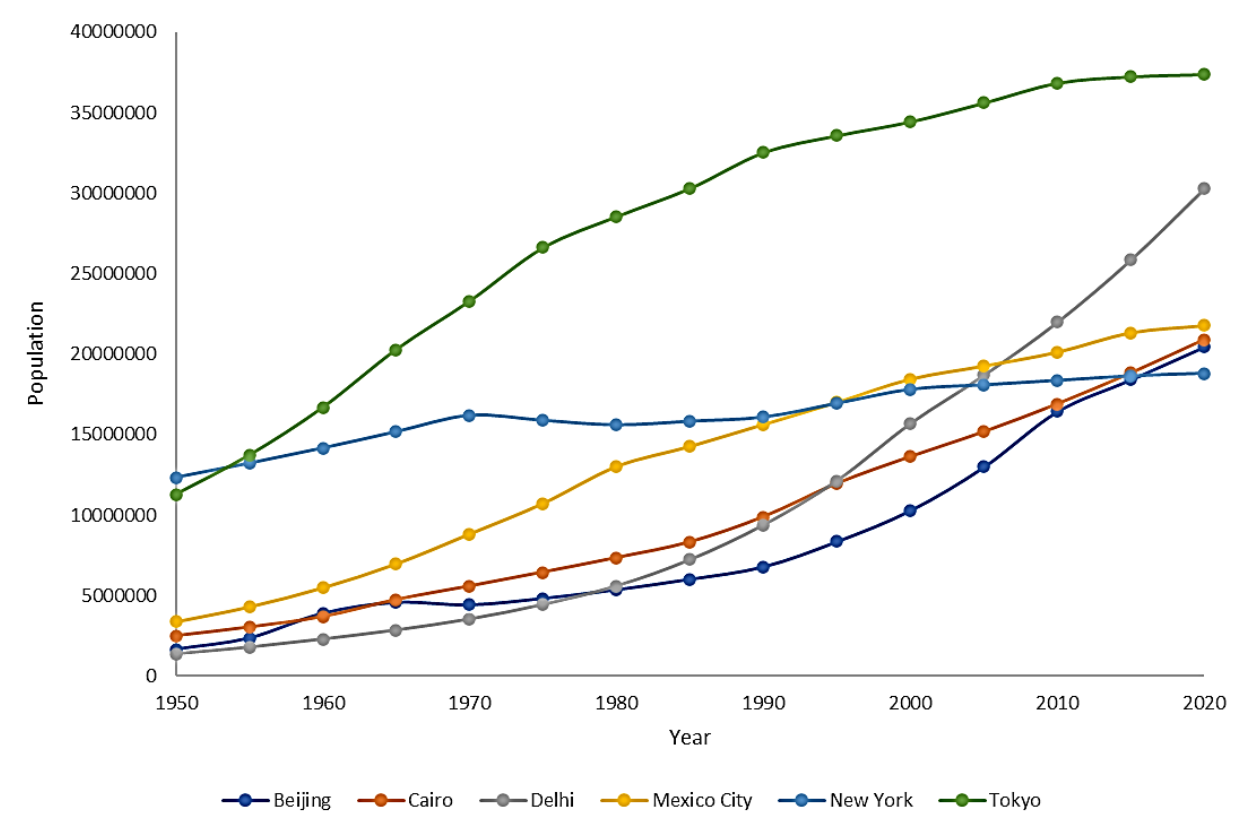

Fig. 1. Urbanization rate and the growth of population in the selected largest cities (1950-2020) Source: [12]

Some cross-sectional studies show a significant rural-urban gap in education outcomes across a wide range of countries $[13,14]$. However, it is unclear how this gap is explained by the spatial division of households and whether it reflects the benefits of cities for the education of their populations. Overall, it seems that regional human capital, measured by education, is a crucial factor for regional development and explains a significant proportion of regional disparities [15]. Employing data from several thousand companies in these regions, the authors note that regional education influences regional development through the training of workers, the training of entrepreneurs and regional externalities [16]. The coefficient of variation representing the human development gap between urban and rural national areas as well as gap between the human development level of urban and rural areas. Based on a trend analysis of the above influencing factors, it can be determined that differences in urban and rural human development all around the world will continue to 
diminish in the future [17]. With regard to differences in education levels, the promotion of policies such as urban and rural integration and urban and rural education should be balanced in order to provide a guarantee of reducing the differences between urban and rural educational levels.

\section{Regional distribution and dynamics of human capital}

In general terms, human capital is a measure of the health, quality of education and standard of living of the world $[18,19]$. The United Nations regularly publishes Human Development Report on human development in various nations with the aim of assessing the rate of human capital formation [20]. The database contains census data for country and covers professional qualifications, innovative employment in the industry and control status. HDI is an indicator that positively correlates with the formation of human capital and economic development [21]. The components of the HDI, life expectancy index, education index and income index are directly related to the formation of human capital in a nation. HDI rates are increasing with higher human capital concentrations that are formed in response to higher education and health standards. Back in the 1980s, Romer (1986) [22] and Lucas (1988) [23] included Human Capital as an independent variable in the growth equation revealing that Human Capital is the main source of economic growth. HDI shows a higher human capital education with good health and education and a higher per capita income in the nations. Education and urbanization contribute to the growth of the human capital while the ageing of the population is having a strong negative impact [24].

But it took longer for human capital to emerge as a key driving force for economic growth. According to American economist Schultz, the father of modern Human Capital Theory, the definition of human capital refers to the knowledge, skills and working capacity of an individual who contributes more to economic growth than physical capital [25]. Based on Schultz's studies, Denison revised the econometric model in 1962 and found that investing in the Human Capital accounted for $23 \%$ of United States economic growth during the period 1929-1957 [26]. Hence, it becomes clear that human capital should be an important factor for innovation and economic development. Long-term impact of human capital on current innovation or economic development has been however a black box, especially at regional level. One can note that using an extensive new dataset on the $19^{\text {th }}$ and $20^{\text {th }}$ centuries regional human capital and other factors, we note that it in the past has been a key factor in explaining regional differences in innovation and economic development currents. Human capital in corporate finance is one of the three primary components of the enterprise (besides intellectual capital and tangible assets) that contribute to the overall value of any business enterprise [27, 28].

Many researchers point to several alternate wave of optimism and scepticism compared to the relevance of human capital to growth since World War II [29]. Against this background it emerges that the high human capital capabilities of the former CMEA member states (the Council for Mutual Economic Assistance, an international economic, scientific, and technical organization which comprised socialist countries before the collapse of the Soviet bloc) improving the prospects for success in the 1990s on the one hand, but also creating incentives for emigration on the other [30]. On the eve of the accession of New Member States (NMS) to the European Union in 2004, the years before and after NMS were characterised by high levels of human capital by GDP per capita. However, as the NMS approached GDP per capita in terms of GDP, some of them moved away. Many productive European workers have tried to emigrate to the United States. As a result, economic growth in Europe has been affected by this migration. The United States and regions with more human capital tend to attract more skilled workers and as a result there has been no convergence between regions [31]. 
With all that, it is interesting to note that tertiary education can serve as indicator of human capital, but literature ignores most of the available human capital because it defines only one type of skill. There is no comprehensive measure that measures the skills of the whole working population [32].

\section{Human capital as a factor of economic growth}

More capital goods, human resources, technology and human capital contribute to the economic growth. The quantity and availability of natural resources can also influence economic growth. The discovery of other natural resources, such as oil and minerals, boosts the economy by increasing the productivity of a country [33].

The effectiveness of a county in the use and exploitation of its natural resources depends on the skills of its workforce, the type of technology and the availability of capital. Human capital has been recognized as an intangible asset whose quality increases workers' performance and benefits the economy [34]. Companies invest in human capital, for example through education and training, which enables improved production quality. In companies, they are called talent management or human resources. Human capital is the economic value of the ability and quality of work that affects productivity, such as education. Investors in human capital for workers are inseparable from this. In other words, human capital is linked to people's ability and efficiency in transforming raw materials into capital goods and services and there is consensus that this ability is learned through the educational system. Human capital development is important for development because it has its own value and development goals [35]. At the micro level, it can be seen as a component of training that contributes to individual labour productivity and income and is an important component of company production. Recent US research has shown that geographical regions that invest in human capital and the economic progress of immigrants living in their countries are helping to boost their short and long-term economic growth. Human capital is one of the important pillars that define the anthropological economy. It is the backbone of the human and economic development of a nation. The tangible contribution of human capital to economic growth of an economy should not be exaggerated. Human capital measures the skills, education and abilities attributed to work that affect their productivity and earning potential.

With regard to this, the Human Capital Index described above measures the contribution of health, education and productivity to the next generation of workers. Countries use the HCI to assess how much revenue they have missed because of the human capital gap and how quickly they can turn it into profits if they act.

Studies have shown that improvements in education can increase productivity, contribute to the development of technologies and improve human capital. In short, human capital theorists argue that a well-educated population is a productive population. Many theories link investment in human capital to the development of education and the role of human capital in economic development, productivity growth and innovation are often cited as justifications for government subsidies for education and training. Human capital is divided into three types: 1) knowledge capital, 2) social capital and 3) emotional capital [36, 37].

However, despite unprecedented progress in human development over the last 25 years, serious challenges still persist for developing countries. There is mounting evidence that countries will not achieve sustainable and inclusive economic growth without strengthening their human capital, will not have a workforce ready for the highly skilled jobs of the future and will not effectively compete in the global economy.

\section{Education and urbanization in human capital growth}


The introduction and growing concentration of the world population in large cities, especially in low- and middle-income countries, means that the relation between urbanization and development has become a major political and economic issue [38]. The biggest practical challenges are in Africa and Asia, where the crucial question is how rapid urban population growth can help raise living standards, reduce poverty and destroy the ecosystems which feed on life. In the last decade many important global development organizations have changed their perspective on this issue, arguing that urbanization should be supported and that growth and development should be promoted. Government policies that promote urbanization or impede urbanization have a major impact on the nature of urbanization, but not all of them have a direct impact on urbanization speed [39].

The return on education is higher in urban areas compared to rural areas and larger and more educated cities compared to smaller and less educated ones. Furthermore, there is an external return to education from urban areas of at least comparable magnitude to private returns. Rural areas are important reservoirs of urban population growth and better educated have a higher chance of moving to cities and acquiring urban hukou. The latter result raises political concerns about urbanisation issues. The expansion of urban land use has surpassed population growth by up to $50 \%$ and 12 million square kilometres of new urban settlements are expected to be added in three decades worldwide. Conflicts are also on the rise, with $60 \%$ of displaced persons living in urban areas [40].

Reducing inequality is one of 17 global goals of the 2030 Agenda for Sustainable Development. Today, 4.2 billion people, lives in cities. By 2050, the urban population will have doubled and 7 out of 10 people will live in a city somewhere around the world [41]. The pressure on the sustainable development and functioning of these cities is going to be enormous. This is why they would require functional programmes for sustaining welleducated and productive population. The investments into the human capital are inevitable and should become an important tool for developing of large population hubs and agglomerations of the future.

The United Nations Sustainable Development Goals-funded program conducts a situational analysis to understand the inequalities underlying these challenges in the communities and countries we work in. The literature on the growth theory points out the importance of human capital in explaining the process of economic development [42]. In this short paper, we highlight the role played by cities in promoting the accumulation of human capital. The process of training the workforce is a kind of investment and capital investment, such as equipment investment, is human capital. Human capital correlates with economic growth, because investment tends to increase productivity. The role of the state is key to raising the skill and education level of a rural population. Governments help to improve human capital by offering free higher education to people. In addition, we think that governments recognize that the knowledge that people acquire from education helps to develop the economy and boost economic growth. Workers with higher education and skill more tend to have higher incomes - which in turn boosts economic growth through additional consumer spending.

\section{Conclusions}

In a conclusion, we can say that human capital can be defined as the collection of knowledge, skills and other personal characteristics that embody people who help them to be productive. The continuation of formal education from early childhood through formal school system to adult education programmes and informal learning and work experience is therefore a valuable investment in human capital.

We can state that the relationship between human capital development and urbanization can be examined by highlighting institutional factors. Moreover, it appears that the return to 
education is higher in urban areas compared to rural areas, and higher in highly educated cities compared to smaller, less educated cities. Additionally, external returns from urban areas on education are at least comparable to the size of private returns. Rural areas are important reservoirs of urban population growth and the better educated have a higher chance of moving to cities and the pursuit of urban hukou. A sustainable urbanization process requires the ease of hukou restrictions, raising the level of education of rural populations, training rural and urban migrants and ensuring equal opportunities for all citizens.

Furthermore, one has to remember that the relationship between urbanization and development is a major political concern for Africa and Asia. The World Development Report paid particular attention to Africa because of the unprecedented potential of its urban areas to stimulate growth. Urbanization offers many economic, social and environmental opportunities and population growth in low and middle-income countries is one of the greatest global challenges of the $20^{\text {th }}$ century. The experience of accelerated economic growth in Africa over the past decade provides a new context for examining the relationship between urbanization and development. The growing recognition by leading global organizations and intellectuals that urbanization is relevant for socio-economic development is important in light of the tradition of city neglect in mainstream economic theory, policy and practice.

Additionally, urbanization uses two concepts to distinguish between urban growth. Urbanization refers to a percentage of the total population living in urban areas, while urban growth refers to an absolute number of people living in these areas. Urbanization growth varies from region to region. Growth in urban areas is due to the increasing migration to cities and the feminization of urban population. Much of urban migration is driven by rural populations who want the benefits that urban areas offer. Benefits offered by urban areas include enhanced opportunities for education, health care and services like entertainment. Amenities such as parks, theatres, museums, restaurants and universities make the Metropolitan Areas more attractive to skilled workers and they also accommodate more educated people. As a result, people with higher education tend to live in urbanized regions, making them more productive.

The agglomeration of the economy and the attraction, accumulation and production of human capital are important factors that explain why metropolitan regions tend to be richer. Higher levels of human capital in metropolitan regions do not drive migration, but rather reflect local, more educated metropolitan areas.

Finally, a few words can be said regarding the issue of fertility and human capital. The fertility difference between urban migrants and rural women exaggerates the effects of urban migration on fertility. In urban areas, women who migrate from rural areas have more children than children born in urban areas. Female rural migrants to urban areas are not an arbitrary selection of the rural population, but they are more likely to want fewer children than if they had stayed in the rural areas. Fertility rates in cities are lower in some parts of the world than in rural areas, which contributes to the growth of urban areas. A similar problem affects developing countries where rising inequality is the result of rapid urbanization trends. In many developing countries' economies are growing rapidly, but growth is unpredictable and relies on a small number of industries. In many cases, low- and unskilled migrants from rural and urban areas are attracted to economic opportunities in urban areas but are unable to find work or afford housing in urban slums. All of these creates regional gaps in human capital and hinders its development and growth. And all of these creates many challenges for the SDG-driven task forces and regional initiatives that need to tackle these issues.

\section{References}

1. Z. Ahmed, M. Asghar, M. Malik, K. Nawaz, Resources Policy, 67, 101677 (2020) 
2. B. Fraumeni, J. He, H. Li, Q. Liu, Journal of Comparative Economics, 47(4), 853-866 (2019)

3. J. Trinidad, International Studies in Sociology of Education, 29(4), 344-365 (2020)

4. Y. Chen, Z. Fang, Economic Modelling, 69, 205-219 (2018)

5. OECD, https://stats.oecd.org/ (2021)

6. W. Strielkowski, Y. Tumanyan, S. Kalyugina, Economics and Sociology, 9(2), 293-302 (2016)

7. C. Kottaridi, K. Louloudi, S. Karkalakos, International Business Review, 28(2), 375-390 (2019)

8. H. Li, P. Loyalka, S. Rozelle, B. Wu, Journal of Economic Perspectives, 31(1), 25-48 (2017)

9. R. Huggins, D. Prokop, P. Thompson, Entrepreneurship \& Regional Development, 29(34), 357-389 (2017)

10. A. Rodríguez-Pose, M. Storper, Urban Studies, 57(2), 223-248 (2020)

11. A. Minh, N. Muhajarine, M. Janus, M. Brownell, M. Guhn, Health \& Place, 46, 155-174 (2017)

12. United Nations, https://population.un.org (2021)

13. D. Lagakos, Journal of Economic perspectives, 34(3), 174-92 (2020)

14. A. Fagbamigbe, N. Kandala, A. Uthman, Scientific Reports, 10(1), 1-15 (2020)

15. M. Smętkowski, European Planning Studies, 26(2), 256-278 (2018)

16. I. Cabelkova, W. Strielkowski, Society and Economy, 35(4), 513-529 (2013)

17. L. Chen, W. Cai, M. Ma, Science of The Total Environment, 741, 138722 (2020)

18. S. Azizi, Economic Modelling, 75, 377-396 (2018)

19. Y. Gruzina, I. Firsova, W. Strielkowski, Economies, 9(2), 67 (2021)

20. United Nations, http://hdr.undp.org (2020)

21. A. Grigorescu, E. Pelinescu, A. Ion, M. Dutcas, Sustainability, 13(4), 2020 (2021)

22. P. Romer, Journal of Political economy, 94(5), 1002-1037 (1986)

23. Lucas R. Journal of Monetary Economics, 22(1), 3-42 (1988)

24. A. Cieślik, J. Michałek, J. Mycielski, Czech Journal of Social Sciences, Business and Economics, 5(2), 6-15 (2016)

25. T. Schultz, The American Economic Review, 51(1), 1-17 (1961)

26. E. Denison, The Sources of Economic Growth in the United States and the Alternatives before Us. Committee for Economic Development (1962)

27. X. Xu, C. Liu, Energy, Sustainability and Society, 9(1), 1-10 (2019)

28. Y. Yusoff, M. Omar, M. Zaman, S. Samad, Journal of Cleaner Production, 234, 626-637 (2019)

29. C. Diebolt, R. Hippe, Applied Economics, 51(5), 542-563 (2019)

30. A. Abonyi, I. Sylvain, Perspectives for Change in Communist Societies (2019)

31. M. Simionescu, Economic research-Ekonomska istraživanja, 32(1), 3607-3626 (2019)

32. M. Zafar, S. Zaidi, N. Khan, F. Mirza, F. Hou, S. Kirmani, Resources Policy, 63, 101428 (2019)

33. M. Haseeb, S. Kot, H. Hussain, F. Kamarudin, Journal of Cleaner Production, 279, $123596(2021)$ 
34. O. Akinlo, J. Olayiwola, The International Journal of Business and Finance Research, 11(1), 77-85 (2017)

35. A. Di Fabio, J. Peiró, Sustainability, 10(7), 2413 (2018)

36. B. Thapa, A. Singh, Journal of Training and Development, 4, 12-23 (2019)

37. M. Alawamleh, L. Ismail, D. Aqeel, K. Alawamleh, Journal of Innovation and Entrepreneurship, 8(1), 1-17 (2019)

38. J. Beall, Social policy and urban development. Handbook of Social Policy and Development (2019)

39. M. Chen, C. Ye, D. Lu, Y. Sui, S. Guo, Journal of Geographical Sciences, 29(10), 16811698 (2019)

40. J. Wennersten, D. Robbins (eds.), Rising tides: climate refugees in the twenty-first century (2017)

41. E. Holt-Giménez, Can we feed the world without destroying it? (2019)

42. S. Marginson, Studies in Higher Education, 44(2), 287-301 (2019) 